\title{
Corrigendum
}

\section{Mammary analog secretory carcinoma, low-grade salivary duct carcinoma, and mimickers: a comparative study}

Todd M Stevens, Andra O Kovalovsky, Claudia Velosa, Qiuying Shi, Qian Dai, Randall P Owen, Walter C Bell, Shi Wei, Pamela A Althof, Jennifer N Sanmann, Larissa Sweeny, William R Carroll, Gene P Siegal, Martin J Bullock and Margaret Brandwein-Gensler

Modern Pathology (2017) 30, 312; doi:10.1038/modpathol.2016.195

Correction to: Modern Pathology (2015) 28, 1084-1100; doi:10.1038/modpathol.2015.64; published online 19 June 2015
In Table 2 of this paper, for Case 2, under the 'Treatment' column, 'Parotidectomy, adjuvant radiation' should be 'Thyroidectomy, tracheal resection, adjuvant radiation.' 